Eliane Camargo

(Centro de Estudos de Linguas Indigenas da América

CELIA-UMR 8133, França)

\title{
Operadores aspectuais de estado marcando o nome em wayana (caribe)
}

\section{RÉSUMÉ}

En wayana, différents opérateurs aspectuels d'état s'associent au nom (animés et inanimés); quatre d'entre eux sont traités dans la présente étude: - $m e,-\phi$, -tpë et -npë. Ces morphèmes d'aspect, assez productifs associés au nom, expriment des notions d'état comme un continuum à partir d'un «avant» jusqu'à un «après». Le jeu des marques grammaticales et la valeur de l'item lexical peuvent fournir des éléments pour une meilleur compréhension de la conception de la temporalité à travers le système des formes temporelles et aspectuelles, ainsi le travail ici présenté propose appréhender les valeurs d'état des suffixes signalés ci-dessus lorsqu'ils sont associé au nom. Pour ce faire, nous nous baseons sur la théorie de la catégorie de l'aspect-temps développée dans la Grammaire Applicative et Cognitive (GAC, 1990), élaborée par le mathématicien et linguiste Jean-Pierre Desclés (Sorbonne-Paris IV, LALIC).

MOTS-CLÉS: Amazonie; Wayana; Langue caribe; Grammaire; TAM; Syntaxe; Ethnolinguistique.

\section{RESUMO}

Em wayana, diferentes operadores aspectuais de estado prendem-se ao nome (animados e inanimados); quatro deles são tratados no presente estudo: -me, - $\phi$, -tpë e -nрё. Esses marcadores de aspecto, bastante produtivos quando presos a nomes, expressam noções de estado como um continuum a partir de um «antes» até um «depois». Visto que o jogo de marcas gramaticais e o valor do léxico podem fornecer elementos para uma melhor compreensão da concepção da temporalidade através do sistema de formas temporais e aspectuais, a proposta do presente estudo é apreender os valores de estado dos sufixos acima indicados que se associam ao nome em wayana. Para isso, optamos pela teoria da categoria do aspecto-tempo desenvolvida na Gramática Aplicativa e Cognitiva, GAC (1990), elaborada pelo matemático e lingüista Jean-Pierre Desclés (Sorbonne-Paris IV, LALIC).

PALAVRAS-CHAVE: Amazônia; Wayana; Caribe; Gramática; TAM; Sintaxe; Etnolingüística.

${ }^{1} \mathrm{O}$ estudo sobre a categoria do aspecto-tempo em wayana teve seu início no pós-doutoramento realizado na FFLCH-USP entre 1999-2001, com financiamento FAPESP. Uma primeira versão deste trabalho foi apresentado na ANPOLL de 2002. A pesquisa de campo iniciada em 1993 mantém um ritmo anual. 


\section{INTRODUÇÃO}

As noções universais que remetem ao estado, ao processo, ao evento e às atividades são constitutivas do sistema de valores semânticos da categoria aspecto-temporal (Desclés, 1991:171). Com isso, algumas questões fundamentais devem ser levantadas como, por exemplo: como essas noções são expressas, como esses aspectos são apreendidos e por que tipo de marcadores e jogo de oposições? O jogo de oposições estado/processo/ evento e atividade parece-me fundamental para a análise lingüística e cognitiva dos aspectos, pois são essenciais para o entendimento dessa categoria pouco estudada nas línguas amazônicas. Tendo em vista que o jogo de marcas gramaticais e o valor do léxico podem fornecer elementos para uma melhor compreensão da concepção da temporalidade através do sistema de formas temporais e aspectuais, a proposta do presente estudo é apreender os valores de estado que se associam ao nome em wayana ${ }^{2}$. Para a análise dos operadores de estado, tomo como sustento teórico o proposto na Gramática Aplicativa e Cognitiva, GAC (1990), elaborada por Jean-Pierre Desclés ${ }^{3}$. Este autor define o aspecto estado como "uma situação estável, em que todas as fases são homogêneas, sem descontinuidade, sem mudança, sem movimento".

Se o 'aspecto' é uma verbalização da percepção interna da situação temporalizada (Desclés \& Guentchéva, 1997) e que afeta toda a relação predicativa, na literatura lingüística essa categoria é, muitas vezes, tratada sob o prisma verbal, com marcadores aspectuais, ou sob o prisma nominal, com lexemas que expressam intrinsecamente valores aspectuais de telicidade /atelicidade. Em wayana, por exemplo, ao nome - que sintaticamente ocorre como núcleo de um sintagma nominal - diferentes formas de significação aspectual de ‘estado’ são associadas. Dentre essas unidades lingüísticas, uma delas, -tpë/tpï, apresenta diferentes valores de estado. Apresenta ainda uma particularidade semântica diretamente ligada ao semantismo lexical que depende da percepção cognitiva interna do sistema sociocultural do grupo.

As análises propostas a seguir mostram como o wayana organiza o seu mundo referencial e percebe, através de operadores aspectuais, o ‘estado' que pode expressar um estado evolutivo (-me) ou um estado de atividade $(-\phi)$, com um processo subjacente, ou o um 'estado' que ao se referir ao estado anterior indica um processo acabado (-tpë/tpï) ou (-npë/npï), este interpretado em muitas línguas caribe por "ex-”.

Antes de adentrar no estudo do nome aspectualizado, uma breve caracterização da língua é proposta.

\footnotetext{
${ }^{2}$ Pertencente à família caribe, o wayana é falado por cerca de 1.800 pessoas em uma vasta região de fronteira entre o Brasil (rio Paru de Este), na Guiana Francesa (rio Litani) e no Suriname (rios Lawa e Tapanahony). No Brasil, essa língua está perdendo campo de forma veemente para o aparai (língua caribe), devido sobretudo à alfabetização realizada nesta outra língua caribe, fazendo com que os pais wayanas optêm por falar com seus filhos em aparai visando uma melhor alfabetização. Situação verificada entre fevereiro e março de 2006.

${ }^{3}$ Matemático e lingüista, Jean-Pierre Desclés, professor da Universidade de Paris-Sorbonne IV, desenvolveu a Gramática Aplicativa e Cognitiva (GAC), a partir da Gramática aplicativa de S. Shaumyan (1977).
} 


\section{CARACTERÍSTICASGERAIS}

O wayana apresenta uma morfologia afixal (prefixos e sufixos ${ }^{4}$ ). Os prefixos remetem à diátese e à pessoa, e os sufixos ao número, ao modo, à modalidade epistêmica, ao aspecto-tempo. A ordem preferencial dos constituintes é «U/A P Predicado». No plano sintático, o wayana apresenta um sistema cindido, caracterizado por um sistema ergativo/ absolutivo marcado pela $3^{\mathrm{a}}$ pessoa (ele/a o/a), por um sistema ativo/inativo, marcado pelas pessoas da enunciação em relação com a $3^{\mathrm{a}}$ pessoa (eu o, você o, ele me, ele te), e um sistema misto (ergativo e neutro ${ }^{5}$ ) marcado pela relação das pessoas do discurso entre elas (eu te, você me) e por um sistema neutro que estabelece a relação entre a $3^{\mathrm{a}}$ pessoa e o nós exclusivo. Esta língua caribe reconhece diferentes classes lexicais como o nome, o verbo, o adjetivo, o advérbio e a adposição (cf. Camargo, 2006b). Ela apresenta processos morfossintáticos produtivos como a nominalização e a aspectualização do nome.

A predicação em wayana se constrói sobre dois tipos de base: a base verbal e a base não verbal. A primeira é composta de lexemas verbais e a cópula. A segunda é composta de lexemas não verbais. As bases verbais são afixadas, ou seja, conjugada, ao passo que as não verbais não. Apesar de esta língua conhecer radicais prototipicamente nominais, pronominais, adjetivais, adverbiais, verbais e dêiticos, o item lexical emana propriedades predicativas, levando o wayana ao onipredicativo (cf. Launey, 1994 quanto à onimpredicatividade do nahuatl). Língua copular, a distinção dos diferentes valores tanto sintáticos quanto semânticos (identificação, atribuição, localização) expressas pela proposição «X ser $Y »$ recorre a operadores de negação que remetem seja a uma relação permanente (com a posposição negativa tapek), seja a uma relação contingente (com o sufixo-la) (cf. Camargo, 2000a, 2003b).

\section{ONOME}

Morfologia e sintaxe são dois critérios fundamentais que determinam a classe nominal. No campo morfológico, o nome é marcado pela afixação. A indexação do nome remete à pessoa (ï-jum //1 pos-genitor// 'meu pai'). Prendem-se a ele sufixos que remetem à diferentes categorias gramaticais como número (wëlii ' 'mulher' > wëli-ham //mulher-pL// 'mulheres', aspecto-tempo (mule-me //menino-Evol// 'está ficando menino') e marcas derivacionais específicas (-ke 'instrumento': malijake //malija-ke// 'com a faca'). Há nomes que evidentemente não recebem essas ou uma dessas marcas. Sisi 'sol', kapu 'céu' são exemplos. Estes nomes pela natureza semântica deles não recebem a marca de número, tampouco são indexados.

\footnotetext{
${ }^{4}$ Tavares (2005) fala também em infixo o que não aparece no meu corpus.

${ }^{5}$ Ajustamentos morfofonológicos acarretam a realização de dois padrões sintáticos: o ataque nulo requer o padrão ergativo, e o ataque silábico o padrão neutro.

${ }^{6} \mathrm{O}$ número é representado por sufixos e partículas (tom\{o\} coletivo e kom\{o\} paucal). Algumas construções sintáticas apresentam uma combinação dos dois.
} 
Na sintaxe, muitos nomes aparecem como sujeito e objeto de frases (kaikui mule t-ëhe // cachorro.A / menino.U / 3Pos-morder-he // 'O cachorro mordeu o menino' [lit. o cachorro, o menino, sua mordida]), como objeto de posposições ( para // 'é para o menino), como elemento possuidor e como elemento possuído nas construções de posse (mule malija-n //menino / faca-ALIEN // 'a faca do menino').

$\mathrm{O}$ atual estudo trata da marcação do nome por sufixos de valor aspectual e seu semantismo dentro de distintos contextos de comunicação. Processo gramatical bastante corrente em línguas caribes, por exemplo, porém pouco explorado do ponto de vista semântico e de sua representação cognitiva. Tavares (2005) em seu doutorado sobre a gramática do wayana explora a morfologia e seu uso na sintaxe da língua ${ }^{7}$. Essa lingüista apresenta uma análise do sufixo - me, por exemplo, em diferentes contextos gramaticais como com posposições e partículas, enquanto que neste artigo, as análises lingüísticas com este morfema e demais morfemas aspectuais restringem-se à associação de tais sufixos e da combinação destes presos ao nome.

\subsection{A aspectualização do nome em wayana}

Em wayana, o nome recebe diferentes operadores aspectuais de estado; dos quais

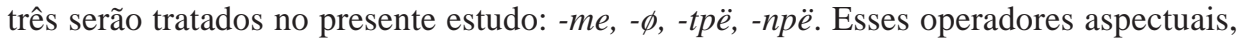
bastante produtivos quando presos a nomes (animados e inanimados), expressam noções de estado como um continuum a partir de um «antes» até um «depois», como ilustra o diagrama abaixo:

(1)

Diagrama dos operadores aspectuais que se associam ao nome

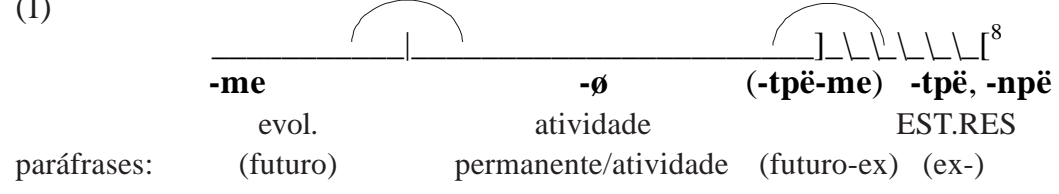

Os sufixos -me e -tpë associam-se ainda a outras classes lexicais (cf. Camargo, 2006a, Tavares, 2005). Preso ao adjetivo, por exemplo, o sufixo - me expressa um processo de uma situação evolutiva, como ilustrado em (2). Ao verbo, o morfema -tpë, de valor participial, remete a um valor de processo acabado, como indicado em (3):

$\begin{array}{ll}\text { mule } & \text { pepta-me } \\ \text { criança } & \text { alta - EVOL }\end{array}$

A criança está ficando alta

${ }^{7}$ Para os sufixos analisados abaixo, os valores aspectuais que atribuímos diferem um pouco da análise proposta por Tavares, por nossos pontos de vista interpretativos diferirem no campo pragmático e cognitivo.

${ }^{8}$ Se basearmo-nos na representação topológica proposta na GAC, a relação predicativa marcada pelo aspecto «estado resultante» ocorre em um intervalo aberto ( ] ) contíguo e posterior ao intervalo fechado ( ] ): _________________/, tendo a parte indicada com barras oblíquas o estado resultante do evento anterior. No ato enunciativo, que é um ato em realização, $\mathrm{T}^{0}$ representa o primeiro instante do não realizado (cf. J. P. Desclés, 1994:60). 
(3) ehuluma-tpë

enforcar-se-EST.RES

Ele está enforcado

A seguir a análise se concentrará apenas nos nomes modificados por tais operadores aspectuais. Tomemos como exemplo, o lexema, kanawa (canoa), representado nos exemplos de (4) a (6), que recebe diferentes valores aspectuais. No exemplo (4), temos o estado de atividade que é o estado visado. Este estado expressa um processo subjacente que se desenvolve em uma parte estável, apresentando um movimento inicial e um movimento final. Vale dizer que o valor de estado não dispõe de um morfema específico, será indicado, no entanto, por um morfema zero, - $\varnothing$. Do ponto de vista pragmático, o exemplo (4) referese à entidade canoa em sua fase de uso social estável, sugerindo a seguinte interpretação literal: «(a canoa) está-se tornando canoa», indicando assim o seu "estado de atividade".

(4) kanawa- $\varnothing$ 'canoa', 'é uma canoa'( lit. '(a canoa) está canoando')

canoa-ATIV

Este item lexical pode apresentar um valor nominal em função argumental (5a). Em (5b), o enunciado mostra que o valor de estado de atividade é expresso em construções nominais:

(5)

a. kanawa aklë-tpï

canoa fazer-part

A canoa está pronta (lit. 'a canoa está feita')

b. hemalë kanawa-me, anumalë kanawa lekën, ametak n-ïtë-ja-i

hoje canoa-evol amanhã canoa ASS aval 3U-ir-incompl-SIT

(lit. 'hoje a canoa está-se tornando canoa, amanhã a canoa estará em atividade, ela descerá o rio')

A canoa está quase pronta, amanhã ela irá em aval

O morfema -me expressa diferentes valores de estado, dentre os quais o de estado permanente, o de estado contigente ou evolutivo e de estado de atividade (cf. Camargo, 2000a). Um dos valores mais produtivo é o de um processo que se dirige a um estado, glosado aqui por evol(utivo), traduzindo uma mudança de estado, como esquematiza a representação topológica abaixo (cf. Desclés, 1989, 1991, Camargo, 2000a):

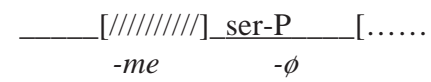

A associação do sufixo -me ao termo nominal kanawa (5b), por exemplo, remete ao estado evolutivo que precede o estado de atividade. Com $-m e^{9}$ também se expressa um

${ }^{9}$ Esse morfema é interpretado como um marcador de equativo, segundo Jackson (1972:73-74) que elaborou uma breve gramática do wayana. 
processo em ação, isto é um início de um processo mas não o seu final, senão o processo se tornaria um evento (Desclés, 1993). Em wayana, este sufixo de valor de estado evolutivo visa o estado de atividade:

kanawa-me Está-se tornando canoa (lit. 'futura canoa')
canoa-Evol

A teoria nativa sugere que a canoa, em (6), esteja no seu processo de fabricação; a canoa ainda não está em atividade social. Esta construção pode ser parafraseada por «futura canoa», pois ela está em processo de se tornar/virar canoa. Este mesmo enunciado pode ser produzido quando o enunciador se depara com uma árvore, cuja madeira é utilizada na fabricação de canoa. Ele se refere à possibilidade da madeira daquela árvore se tornar canoa.

É notável a passagem do emprego do enunciado (6) ao (4). Enquanto a canoa está sendo fabricada ou até mesmo durante o trajeto que, depois de pronta, é empurrada até a beira do rio, o(s) enunciador(es) enuncia(m) (6). Ao jogá-la na água, vão enunciar (4), referindo-se ao estado de atividade que ela começa a exercer.

Com o morfema -tpë/-tpï, o enunciador faz referência ao estado resultante, ou seja, ao término do estado de atividade ${ }^{10}$. O exemplo (7a) expressa que a 'canoa' deixou o estado de atividade no qual se encontrava, deixando de ser operacional, por desgaste material ou por acidentes, como rachaduras sem conserto ou morte do dono, por exemplo. A referência aspecto-temporal é a de um processo completo:

(7a) kanawa-tpë

canoa-EST.RES

Não é mais canoa. (lit. 'ex-canoa')

(7b) Tapin kanawa-tpë

Tapin canoa - EST.RES

(lit. 'ex-canoa do Tapin')

O Tapin deixou a canoa dele

(7c) i-kanawa-tpï

3POS-canoa-EST.RES

A canoa dele está abandonada. (lit. 'ex-canoa dele')

O exemplo (7c) mostra que a forma -tpü ocorre com a presença de um clítico, isto é i- '3POS' e, em uma construção possessiva, a vogal do sufixo aspectual mudar quando o nome é indicializado. Nesse caso, somente a forma -tpï é admitida sintaticamente.

Cabe assinalar que -tpë não remete a noção de velho, mas sim de caducidade. Para expressar o ‘envelhecimento’ de um objeto, por exemplo, o wayana recorre a uma estrutura adjetival como kanawa upakat 'a canoa está velha (mas ainda em uso)', ao passo que em

${ }^{10}$ Tavares interpreta-a como um devaluativo, porém não leva em conta a diferença aspectual

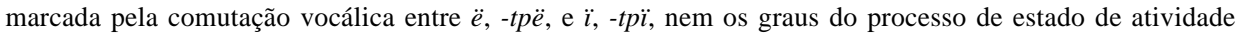
cumprido, que provém de uma representação semântica-cognitiva. 
(7c) o objeto se tornou obsoleto em quanto transporte, mas a sua madeira será reutilizada para outros usos, como em jirau, táboa-suporte para uso doméstico, estante e neste caso, será sempre expresso como kanawatpë. Ou seja, 'uma táboa que antes servira de canoa'.

\subsection{Fenômenos atmosféricos marcados pelo estado}

Os elementos celestes e a referência noturna são interpretados apenas dentro de um estado descritivo.

(8)
a. koko
(É/está) noite
(*koko-me)
b. kokole
(É) meia-noite
$(*$ kokole-me $)$
c. walunak
(É) tardezinha
(*walunak-me)
d. nunuwë
(É) lua
(*nunuwë-me)
e. silikë
(É [uma]) estrela.

A construção silikë-me só é aceita se a referência for celeste e desconhecida, o que implica em uma situação de interrogação quanto à identidade do objeto.

Os termos designadores de fenômenos atmosféricos são todos predicativos. Eles marcados pelo morfema -me expressam um estado contingente $(9 \mathrm{~b}, 10 \mathrm{~b}, 11 \mathrm{~b})$. Essas construções podem receber o sufixo aumentativo -nma de valor adverbial (9c, 10c, 11c). O que é interessante nessas construções metereológicas é a variação semântica do valor do aspecto -me que com fenômenos transitórios como a chuva e o vento marca um processo.

(9)

$\begin{array}{llll}\text { a. } & \text { sisi } & \text { (É o) sol } & \text { (estado descritivo) } \\ \text { b. } & \text { sisi-me } & \text { Está quente/calor } & \text { (estado evolutivo) } \\ \text { c. } & \text { sisi-me-nma } & \text { Está muito quente } & \\ & \text { sol-EVOL-AUM } & \end{array}$

(10)
a. kopë
(É a) chuva
(estado descritivo)

b. kopë-me

Chove.

c. kopë-me-nma

Chove bastante

(11)

$\begin{array}{lll}\text { a. } & \text { taun } & \text { (É o) vento } \\ \text { b. } & \text { taun-me } & \text { Venta } \\ \text { c. } & \text { taun-me-nma } & \text { Venta muito }\end{array}$

(processo em ação, estado em atividade)

(estado descritivo)

(processo em ação, estado em atividade)

\subsection{O valor da relação predicativa «Y-me X-ser»}

No campo predicativo, a especificação de Y pela sufixação de Y remete apenas as relações de atribuição, de localização e de posse. Abaixo apenas a relação atributiva é exemplificada. Ao comparar (12a-12b), observam-se as construções que provêm de um estado permanente e as que provêm de um estado evolutivo ou contingente. A representação topológica abaixo ilustra a distinção aspectual entre o 'estado permanente' 
(12a), que podemos indicar por um morfema zero, e o estado contingente, marcado pelo sufixo -me (12b), que revela o valor de uma mudança de estado, por ter como alvo um estado posterior, marca um estado contingente.

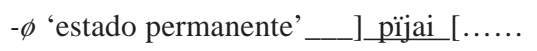

(12) a.

$$
\begin{array}{ll}
\text { pïjai- } \phi & w-a-i \\
\text { xamã-PERM } & 1 \mathrm{U} \text {-ser-sIT }
\end{array}
$$

Sou xamã. (lit. 'Tenho a propriedade de ser xamã')

-me 'estado contingente/evolutivo'

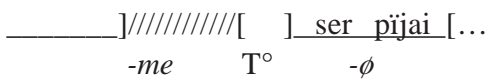

$\begin{array}{ll}\text { b. } \quad \text { pijai-me } & w-a-i \\ \text { xamã-EVOL } & 1 \text { sg-ser-sIT }\end{array}$

Eu viro xamã' (lit. 'Eu me atribuo o processo de me tornar xamã')

Este é confirmado pelo operador de negação -la, permitindo-nos dizer que a proposição «Y-me X-ser» provém de uma relação de atribuição ${ }^{12}$.

$$
\begin{array}{lll}
\text { c. } & \text { pijai-me-la } & w-a-i \\
& \text { xamã-EVOL-NEG } & 1 \mathrm{U}-\text {-ser-SIT }
\end{array}
$$

Eu não viro xamã

\subsection{Categoria etária marcada pelo estado}

O sistema de categoria etária é determinado por seis termos que remete a períodos distintos da vida de um indivíduo. $\mathrm{O}$ item lexical não marcado por nenhuma realização fonológica remete a um estado descritivo. Neste caso, como ilustra o esquema em (13a), trata-se de um estado de atividade social onde cada período remete a tarefas sociais específicas que um indivíduo wayana deve cumprir.

A categoria etária dos homens segue a seguinte sequiência:

(13) a.

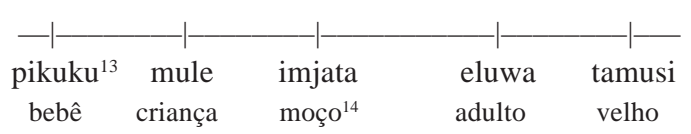

$$
\begin{array}{lll}
\text { b. } & \text { Pasi } & \text { tamusi } \\
\text { Pasi } & \text { velho } \\
\text { Pasi é velho } & \text { (estado descritivo) }
\end{array}
$$

${ }^{12}$ Os operadores de negação tapek e -la desempenham um papel fundamental na predicação nominal do wayana. Eles permitem extrair os valores aspectuais de duas relações predicativas subjacentes: a relação de identificação que remete a estados permantente do tipo «a terra gira» e a relação de atribuição que expressa um estado contigente do tipo «faz calor; está frio» (Ver Camargo, 2003b).

${ }_{13}$ pijukuku na variante da Guiana Francesa.

14 Tradicionalmente "jovem iniciado". 
A associação do sufixo -me, de estado evolutivo, indica um estado transitório que visa um estado de atividade como ilustra o esquema abaixo:

(14)

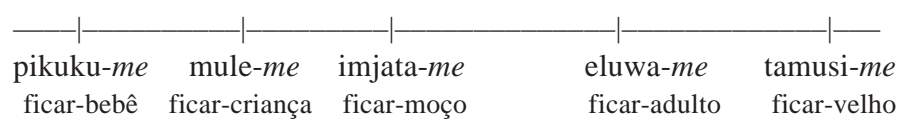

O exemplo (15) é interessante por apresentar dois termos referentes à categoria etária, mostrando a passagem de uma categoria para a outra. Neste exemplo, o termo mule 'criança' não é marcado morfologicamente remetendo ao estado de atividade na qual ele se encontra. O segundo termo é marcado por -me e remete ao estado evolutivo que visa o estado de atividade que é o de imjata 'moço'. O exemplo abaixo sugere assim a seguinte leitura literal: "aquela (que é) criança está-se tornando rapaz, ela (a criança), ela vai ficar":

\begin{tabular}{|c|c|c|c|}
\hline $\begin{array}{l}\text { mëk } \\
\text { aquele }\end{array}$ & $\begin{array}{ll}\text { mule- } \varnothing & \text { imjata-me } \\
\text { criança-PERM moço-EVOL }\end{array}$ & $\begin{array}{l}\text { më } \\
\text { ANAF }\end{array}$ & $\begin{array}{l}\text { n-ëtï-ja } \\
\text { 3A-ficar-INCOMPL }\end{array}$ \\
\hline
\end{tabular}

Vejamos a expressão semântico-cognitiva do estado de atividade. O enunciado (16) revela que a construção eluwa-me refere-se a um jovem que aprende a fabricar arcos e flechas, a tecer cestos ou folhas de palmeira para o teto da casa. Sua entrada na categoria eluwa 'homem adulto' indica que ele já detém este conhecimento e efetua tais artefatos de forma autônoma:
a. mule-me-la
eluwa-me
menino-EVOL-NEG homem-EVOL

Ele não é mais um/a menino/criança, ele está-se ficando um homem adulto

$\begin{array}{llllll}\text { b. Matapi } & \text { kanawa } & \text { pëtuku } & \text { m-ïlï } & \text { eluwa-me man-a-i } \\ \text { Matapi } & \text { canoa } & \text { bonito } & \text { 2A3P-fazer.COMPL homem-EVOL 2U-ser-SIT }\end{array}$
Matapi, você fez uma bela canoa, está ficando (homem) adulto

O morfema -tpë/-tpï indica a saída do estado de atividade, remetendo assim ao fim de um processo incompleto. $\mathrm{O}$ fim desse processo incompleto poderia ser interpretado como o estado resultante de um processo subjacente, completo.

\begin{tabular}{|c|c|c|c|c|}
\hline $\begin{array}{l}\text { pijukuku-tpë } \\
\text { ex-bebé }\end{array}$ & $\begin{array}{l}\text { mule-tpë } \\
\text { ex-criança }\end{array}$ & $\begin{array}{l}\text { imijata-tpë } \\
\text { ex-jovem }\end{array}$ & $\begin{array}{l}\text { eluwa-tpë } \\
\text { ex-adulto }\end{array}$ & $\begin{array}{c}\text { tamusi-tpë } \\
\text { ex-velho }\end{array}$ \\
\hline
\end{tabular}

Os enunciados nas seções seguintes indicam que o estado de atividade do indivíduo dentro da categoria etária wayana chega ao seu fim. 


\section{RELAÇÃO ENTRE FORMAS E SIGNIFICAÇÕES COM OS SUFIXOS-TPË E-NPË}

O wayana mostra uma gramaticalização forte, com formas de significado transparentes. A unidade lingüística, -tpë, expressa outras significações menos transparentes, pois o significado pode variar dependendo da natureza semântica do lexema ao qual se associa. Em muitos casos, a construção «nome-tpë» expressa noções que em nossas línguas seriam interpretadas como modalidades de ação (aktionsart). Isso mostraria uma contradição do ponto de vista da aspectualogia que no que se refere a estas modalidades considera os lexemas mais transparentes que as gramaticalizações. Todavia, em wayana, tais valores de modalidades de ação são explícitos pela teoria nativa que sugere interpretações da construção «nome-tpë» como findar, continuar a, terminar de, cessar. Vejamos como essas noções de natureza cognitiva são expressas nessa língua caribe.

\section{1. -tpë-me: findativo (fim de)}

Dentre esses operadores aspectuais, somente a combinatória tpë-me é admitida ${ }^{15}$, expressando um «findativo». Isto é, o início do fim do estado de atividade com um processo interno. A paráfrase «futuro-ex» expressa esse início da saída do estado de atividade. Do ponto de vista pragmático, a interpretação de (18) revela que a canoa começa a ser uma futura-ex canoa, estando prestes a deixar o «estado de atividade».

\section{2. -tpë: terminativo (terminar de)}

Com -tpë, tem-se também a fase acabada e posterior do «estado de atividade», que poderia ser interpretado como um «terminativo». Este valor terminativo é bastante produtivo para marcar a mudança de categoria etária ${ }^{15}$, mas não somente ela. Comparar os exemplos de (19) a (22). Em (19), a associação de -tpë ao termo eluwa 'homem-adulto' indica que a entidade eluwa deixou esta categoria e agora está na categoria seguinte, na dos tamusi (18b). A referência é ainda feita às propriedades atribuídas, como pessoa ativa, forte, trabalhadora, que o tamusi era quando estava na categoria dos eluwa 'homens-adultos':

(19) eluwa-tpë ex-adulto (passou a tamusi 'idoso')

O tamusi ocupa o grau mais alto da categoria etária, sendo considerado o 'representante vivo da ancestralidade'. Entretanto, em (20), a associação de -tpë a este termo não indica uma mudança de categoria etária. Ela faz referência ao seu estado resultante. Isto é, à categoria do eluwa, na qual o tamusi, enquanto eluwa ocupara funções de um homem de responsabilidade sócio-política, como organizador de reuniões, por exemplo:

${ }^{15}$ Esta combinatória é produtiva com lexemas verbais, que no enunciado a seguir sugere a interpretação de um subjuntivo passado: ëtato-me uwa mühen pakila ëtuku-tpë-me lëken t-onop-he (lugar-evol / sem / coitado / caititu / comer-tpë-me / ass / 3-pintar-TAM) 'coitadinho dele, ficou pintado como se o caititu tivesse comido. Extraído do mito do Tulupele.

15 Baseio-me aqui na categoria etária masculina. 
(20) tamusi-tpë ex-organizador, responsável de reunião

(agora é um tamusi sem o poder de antes)

Em (20), o adulto não responde mais por suas atividades sociais como a caça, a construção de canoa. Ele não está mais dentro desta categoria. Ele passa para última das categorias que é a classe dos velhos (tamusi) sábios (tuwalon). Pragmaticamente, o enunciado acima não indica a caducidade desta categoria etária, por ser a última delas, mas designa o papel social ocupado por alguns indivíduos quando estavam na classe dos adultos.

\section{3. -tpë: cessativo (cessar de)}

O morfema -tpë pode expressar um valor aspectual «cessativo», indicando um estado final. Os exemplos (21) não tratam de uma mudança de categoria de jovem-iniciada à mulher-adulta ou de jovem iniciado a homem-adulto. Estas construções referem-se a um jovem-iniciado recém-falecido (21a) ou a uma jovem-iniciada recém-falecida (21b). Isto é, cessaram de existir e passaram ao estado final da zona aspecto-temporal marcada por um continuum:

(21) a. imjata-tpë

'jovem recém-falecido' (lit. 'ex-jovem-iniciado')

b. waluhma-tpë

'jovem recém-falecida' (lit. 'ex-jovem-iniciada')

A interpretação deste 'cessativo' depende da semântica do lexema. No enunciado (21a), por exemplo, a construção, marcada por -tpë, refere-se a uma morte recente. Para indicar a mudança de categoria etária dos termos em (22), introduz-se uma combinatória

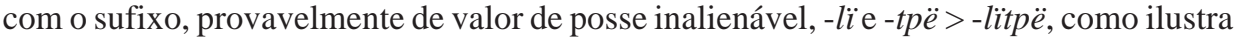
o exemplo abaixo ${ }^{16}$. Este enunciado sugere a leitura de um jovem-iniciado que não é mais rapaz. Este passou agora à categoria dos homens-adultos, i.é. à categoria dos eluwa:

(22) imjata-li-tpë

'ex-jovem (não é mais um jovem-iniciado)'

jovem-li-tpë

A noção de cessativo não é restrita ao wayana. Em tiriyó, outra língua caribe, também conhece um cessativo - $k e(p \ddot{\imath})$ que se associa a nomes com o sentido de 'parar de' e sua ocorrência parece ser produtiva com termos relativos a partes do corpo (Meira, 1999:277). O kamaiurá, por sua vez, também conhece um cessativo com o morfema -pik (Seki, 2000:133 $)^{17}$.

${ }^{16} \mathrm{O}$ sufixo -lï junto a termos de parentesco indica um valor de inalienabilidade, quando de uma construção negativa, por exemplo: emsi-li-mna wai 'não tenho filha' (filha-INALIEN-PRIV, lit. estou sem/ desprovida de filha).

${ }^{17}$ Ao contrário das línguas caribes, este sufixo parece agregar-se apenas ao verbo como indicam os dados fornecidos por Seki. Seria interessante ver se este morfema aparece preso a um nome nessa língua tupi-guarani, e em caso afirmativo ver qual é seu valor aspectual expressado. 


\title{
4.4. O estado revoluto: -npë
}

O morfema -npë de valor participial remete a ultrapassagem de uma fronteira a partir de um estado. Ele refere-se a um estado acabado. Vejamos a sutileza dos valores semânticos de -tpë, que remete a um estado caduco para os elementos inanimados e a um estado resultante para os animados, e de -npë que remete a um estado antigo. Do ponto de vista aspectual, -tpë remete a um estado completo e -npë a um estado acabado ${ }^{18}$.

Em (23), -tpë está associado a um nome animado. Se tomarmos em termos de operação temos em (23a) «X deixou seu estado». Isto quer dizer que antes «X era jovem (estado de atividade)», mas em (23b) «o estado de X é antigo». Ou seja, X não existe mais. Ele deixou o estado de atividade, sem ultrapassar a fronteira de sua categoria etária. Ele está morto.

(23) a.

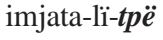 \\ jovem-INAL-EST.RES \\ (lit. O jovem não é mais) \\ Ele não é mais tão jovem (como antes)
}

b. imjata-lï-npë

jovem-INAL-EST.REV

O jovem está morto

\section{MUDANÇA DE REFERENCIALIDADELEXICAL}

Em alguns casos, a aspectualização do nome implica em uma mudança do referente lexical. Vejamos isso analisando nomes animado humano, marcados pelos diferentes sufixos aspectuais. Os exemplos abaixo permitem apreender por comutação sutilezas semânticas do referente lexical. Os exemplos em (24a-25a) é um processo em se tornar que é expresso, ao passo que em (24b-25b) é a propriedade do estado que é atribuído.

Em (24a), «X, mãe de Y» está no processo de se tornar mãe (outra vez) ${ }^{19}$, em (24b), ao contrário, é a propriedade de «X ser mãe de Y» que é expressa.

\begin{tabular}{|c|c|c|}
\hline & processo em curso & atribuição de propriedade \\
\hline 24. & $\begin{array}{l}\text { a. mule } \quad \text { i }- \text { je }- \text { me } \\
\text { criança } \quad \text { 3POS-genitora-EVOL } \\
\text { A mãe da criança está grávida (de novo) }\end{array}$ & 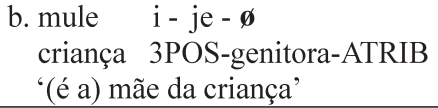 \\
\hline 25. & $\begin{array}{l}\text { a. i - pït - me } \\
\text { 3POS-esposa-EVOL } \\
\text { Ela se torna uma esposa (, mas ainda não é) } \\
\text { (referência a uma mulher) }\end{array}$ & $\begin{array}{l}\text { b. i - pït - } \varnothing \\
\text { 3POS-esposa-ATRIB } \\
\text { '(é a) sua esposa' } \\
\text { (referência a um homem) }\end{array}$ \\
\hline
\end{tabular}

${ }^{18}$ Camargo 2000a define a distinção entre aspecto completo ou cumprido (accompli) e aspecto acabado (achevé).

${ }^{19}$ A gravidez pode ser também expressa por munome. 
Os nomes marcados pelo sufixo -tpë também podem apresentar mudança semântica dependendo da perspectiva semântica. Trata-se de nomes da categoria etária, porém aqui remetem sematicamente a uma ligação seja biológica, como a de filhos e pais, seja de aliança como a de esposos, ocorrendo uma mudança na referencialidade semântica do nome. Por exemplo, em (26) o lexema pikuku designa 'bebê' (até a fase de iniciação), a associação de -tpë a este radical não remete a um estado anterior (o do período fetal), tampouco a de um estado cessativo da criança, no sentido de ex-criança recém-falecida. A referencialidade aqui é a morte/perda específica da mãe da criança. O exemplo (26) remete à orfandade. A criança é concebida como ex-criança devido à morte da mãe. Ela não está mais no estado de 'estar sob os cuidados/educação da mãe':

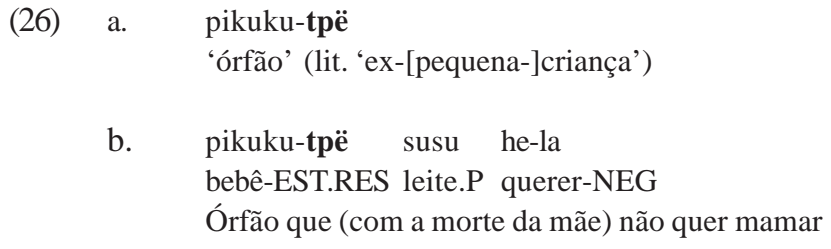

Jackson (1972:66) interpreta este morfema como um terminativo, indicando uma posse terminada. Outros autores caribistas compartilham a mesma interpretação para -tpë como 'terminativo' ou 'cessativo' (Gildea, 1998; Meira, 1999). Porém, as distintas zonas aspecto-temporais que essa unidade lingüística marca não são mencionadas. Vimos que, ao menos em wayana, o valor de tal forma remete a mudanças de valor de estado como também de referencialidade lexical. No caso acima, a teoria wayana revela uma mudança de estado: a 'criança deixa de ser criança', atingindo um outro estado - o de não dependência da mãe. Até mesmo, por ela não mais existir.

Com o termo wëlïi 'mulher', a associação do sufixo -tpë remete a uma expressão jocosa entre homens. Ao contrário do exemplo (19) com eluwa-tpë referindo à categoria etária anterior do tamusi 'velho', com (27), a referência não é a de uma posição de prestígio que a kunumusi 'velha' tenha ocupado enquanto pertencia à categoria das wëlïi 'adultas'. A construção abaixo se refere ao 'homem que está com cara de mulher', tendo um comportamento não condizente ao de um homem forte, trabalhador, que não teme nada'.

(27) wëlïsï-tpë

mulher-tpë

O homem está com cara de mulher (lit. 'ex-mulher')

Com termos de parentesco tem-se alguns exemplos em que a associação do sufixo -tpï preso ao nome remete a um estado acabado. Os termos -mnelum 'esposo'

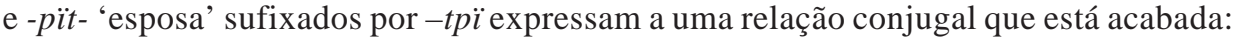

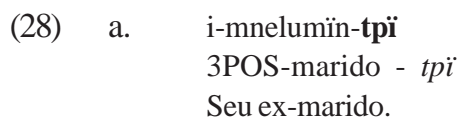


b. $\quad$ i-pï $\{t\}-$ tpï

3POS-esposa-tpï

Sua ex-esposa

O morfema -tpë remete indiscutivelmente a um estado anterior, porém a pragmática desempenha um papel importante e requer do leitor uma atenção particular em relação ao referente semântico. Tomemos dois termos referentes a alimento. Uma caça, o 'catitu' pakila, e uma parte do corpo da caça, o 'fígado' ële. O sufixo -tpë associado ao nome da caça (29a) remete ao estado não apropriado ao consumo desta, por seu mal cozimento. Ao passo que este sufixo preso ao nome que designa uma parte do corpo da caça (29b) remete ao bom estado de cozimento do fígado, indicando que ele está bom para ser consumido.

(29) a. pakila-tpë

catitu-tpë

O catitu está moqueado, mas não bem cozido, então não está bom para ser consumido

b. $\quad \varnothing$-ele-tpë

3POS-fígado-tpë

O fígado (dele) está cozido e pronto ao consumo

Vejamos um outro exemplo. Desta vez com o nome inanimado que designa 'bebida'. Este nome apresenta uma variação morfológica, o termo que remete ao valor genérico -wokï, e aquele que remete ao valor específico -ok. O semantismo pragmático dessas construções aspectualizadas difere, pois em (30a) a 'bebida torna-se de X sem que X tenha consumido', enquanto que em (30b) 'bebida também é de X, porém já consumida por X':

(30) a. ï-wokï-me

1POS-bebida-EVOL

É minha bebida (, ainda não consumida)

b. j-ok-me

1POS-boisson-EVOL

É minha bebida (, já consumida)

Do ponto de vista pragmático, três dos termos da categoria etária marcados por -npë requerem uma leitura de mudanca de referente. Para examiná-lo, tomemos primeiramente as diferentes marcas de valor de estado que se associam ao nome mule 'criança'. O estado evolutivo é marcado por -me (31a), o valor de estado de atividade não é realizado fonologicamente (31b) o estado anterior é indicado por -tpë $(31 \mathrm{c})^{20}$ e o estado revoluto é marcado por - nрё (31d):
(31)
mule-me
Ele se torna mule
(X entra na categoria dos mule)
b. mule-ø Ele é um mule
(X assume o papel social na categoria dos mule)

${ }^{20}$ A construção muletpë apresenta uma lexicalização designando o 'caçula'. 
CAMARgo: Operadores ASPECTUAis de ESTAdo MARCANDO O NOME...

$\begin{array}{lll}\text { c. mule-tpë } & \text { Ele é um ex-mule } & \text { (X deixou a categoria dos mule) } \\ \text { d. mule-npë } & \text { Ele era mule } & \begin{array}{l}\text { (X deixou ser ser mule pela perda de um dos } \\ \text { ou de seus pai/s) }\end{array}\end{array}$

Se em (31d), o sufixo -npë, associado a mule indica que a criança é 'órfã', esse morfema está semanticamente ligada à perda de um de seus pais biológicos ou dos dois. A leitura literal sugere a interpretação seguinte: «a criança não está mais no estado de atividade de ser criança». Ela tem a particularidade de não contar com seu(s)/sua genitor(es)/ a. Este mesmo morfema preso aos nomes -je 'genitora' e -jum 'genitor' assinala que os pais perderam um ou mais de seus filhos. A interpretação literal em (32) é «a mulher não está mais no estado de ser genitora pela perda do filho».

(32) a. je-npë $\mathrm{X}$ era genitora de $\mathrm{Y}$ (que morreu)

b. jumï-npë $\mathrm{X}$ era genitor de $\mathrm{Y}$ (que morreu)

A aspectualização operada por valores de estado afeta também construções possessivas. Dentre os termos de parentesco de valor referencias, tomemos aqueles que designam 'esposo' -mnelum e 'esposa' -püt. A escolha estes lexemas parece-nos interessante por remeter a referentes, a gêneros diferentes. (33a) remete ao homem que não tem mais esposa e (33b) remete a mulher que perdeu o marido por óbito.

a. $\quad$ i-pï $\{t\}-$ tpï

Ele é separado (da mulher). (referencial masculino)

(lit. «X é ex-esposado». Ele não está mais no estado de ser casado)

b. i-pï $\{t\}-\mathbf{n p i ̈}$

Ela é viúva (referencial feminino)

(lit. «X é viúva». Ela não está mais no papel de ser casada)

O sujeito lógico desses enunciados não é o mesmo. Trata-se de um homem em (33a) e de uma mulher em (33b). Estas mudanças de referentes não implicam em nenhuma mudança no valor de estado desses morfemas. Um estado anterior (ultrapassagem da fronteira) com -tpï é um estado antigo (com fim do estado), marcado por -npï.

\section{CASOS DE LEXICALIZAÇÃ̃o}

O wayana apresenta casos de lexicalização bastante interessantes, tanto com o sufixo -me quanto com -tpë/-tpï.

\subsection{Lexicalização com o sufixo -me}

Trata-se dos termos que designam 'saúde' e 'doença'. Eles são construídos a partir de um processo derivacional com o sufixo -me, em um caso, seguido do sufixo de negação -la, no outro. A raiz uwa em seu emprego isolado designa o advérbio de negação, não. 
(34)

a. uwa-me

não-EVOL

Ele/a está com saúde

b. uwa-me-la não-EVOL-NEG

Ele/a está doente

\begin{tabular}{|c|c|c|c|c|}
\hline \multirow[t]{4}{*}{ c. } & mule-me & ïw-aptau & uwa-me-la & w-eha-ken \\
\hline & criança-EVOL & 1-quando & não-EVOL-NEG & 1U-ser-ACABADO \\
\hline & moloinë & ï-wona-imë-ne & & \\
\hline & mas & 1U-sarar-REV-A & ADO & \\
\hline
\end{tabular}

\subsection{Lexicalização com o sufixo -tpë/-tpï}

Os processos de lexicalização de uma construção sintática são distintos. Os dados dos quais dispomos revelam construções genitivas. Vejamos exemplos que tratam de termos de parentesco e de partes do corpo.

Com os termos de parentesco, tem-se, por exemplo, iwotpë 'irmã do pai', i.é. sogra, enunciado somente por homens, que tem um significado genérico. Vejamos o processo morfossemântico de -wotpë. O radical -wo designa $\mathrm{MB}^{21}, \mathrm{FZH}^{22}$ ou seja 'irmão da mãe', 'marido da irmã do pai' (ego masculino falando), ao associar-lhe o sufixo -tpë acarreta uma mudança do gênero do referencial de 'homem' passando a 'mulher', pois -wo-tpë FZ ${ }^{23}$, $\mathrm{MBW}^{24}$ refere-se a 'irmã do pai', 'esposa do irmão da mãe', ou seja sogro em um caso e sogra no outro. A lexicalização seria a de uma construção genitiva fixa em que ëwotpë remete ao termo genérico. Na relação de pertencimento, os índices pessoais se comutam e a vogal ë- remete à 2a pessoa: ëwëtpü. Nessa construção, a lexicalização sofre algumas modificações fonéticas: a vogal do radical $o$ se realiza $a$, e o sufixo de estado resultante em função genitiva é alterada de $\ddot{e}$ para $\ddot{i}: \ddot{e} w \underline{\boldsymbol{o}}$ tp $\underline{\ddot{\boldsymbol{e}}}$ 'sogra' (genérico) e ëw $\underline{\ddot{\boldsymbol{e}}} t p \underline{\ddot{\boldsymbol{u}}}$ 'a tua sogra' (específico).

Dois dos termos referentes às partes do corpo humano, 'cabeça' e 'osso', apresentam em sua sílaba final -tpë e -tpï. Se desmembrarmos esta sílaba da palavra, o locutor nativo não reconhece o que seria a raiz ( ири em upu-tpë 'cabeça' e je em je-tpë 'osso' ${ }^{25}$ ); processo morfológico que aponta que essas sílabas derivam do morfema aspectual de estado -tpël -tpï. Vimos acima que por comutação vocálica, a forma em -tpï remete à uma construção genitiva, sugerindo uma relação determinada, definida, ao passo que -tpë remete a uma acepção genérica, não determinada, não definida:

\footnotetext{
${ }^{21}$ Mother's brother.

22 Father's sister's husband.

${ }^{23}$ Father's sister.

${ }^{24}$ Mother's brother's wife.

${ }^{25}$ Apesar de que encontramos -je- em jelï 'dente' : $\phi$-je-lï //3pos-dente-inal// 'o dente de'.
} 


\begin{tabular}{|l|l|l|}
\hline & \multicolumn{1}{|c|}{ forma genérica } & \multicolumn{1}{c|}{ forma específica } \\
\hline 35. & a. uputpë ‘(a) cabeça' & $\begin{array}{l}\text { b. } \varnothing \text { - uputpï } \\
\text { 3POS-cabeça.POS } \\
\text { '(a) sua cabeça' }\end{array}$ \\
\hline 36. & a. jetpë ‘(o) osso' & b. ø - jetpï \\
& & 3Pos-osso.POS \\
& & '(o) seu osso' \\
\hline
\end{tabular}

Há lexicalizações também com o sufixo de estado revoluto -npë:

(37) a. mune mu - npë (sangue / sangue ${ }^{26}$-npë) 'útero'

b. mule-po-npë (criança-Loc-npë) 'placenta' (lit. 'local onde está a criança')

Com termos inanimados, a forma -tpë como sílaba final é bastante produtiva. O que ocorre nos casos abaixo é que a comutação pela forma de possessivo -tpï não é admitida nesses lexemas o que sugere que aqui não se trate de lexicalização, mas sim de lexemas plenos.
(38)
a. tutpë
'balde' (*tutpï)
b. ëluwëtpë
‘cinza' (*ëluwëtpï)

Abaixo, o lexema mïtpë (> mït-tpë (?)) poderia ser interpretado como um nome aspectualizado, em que o sufixo -tpë fizesse referência à saída do estado anterior, isto é à saída do estado de atividade, literalmente interpretado como 'ao estar enraizando' passara a 'enraizado', ou seja a 'pedaço', a 'toco'.
(39) a
wewe mïtpë 'pedaço/toco de pau'
b. malija mïtpë 'pedaço/toco de faca'

O mesmo ocorre com a metáfora ëlëk patatpë (ferida / aldeia-tpë) que designa 'cicatriz' interpretada como 'ex-aldeia de ferida'.

Com a sílaba -npë dispomos de um exemplo, kanpë 'moqueado'. Poderíamos pensar que tal lexema provenha de uma derivação, em que $k a$ seja a raiz que designa 'peixe', seguida do sufixo aspectual -npë. Culturalmente nada justifica que a sílaba $k a$ - faça referência à 'peixe', tampouco por serem hoje um povo pescador. Os Wayana, outrora habitando o interior das terras, eram um povo cinegético.

${ }^{26}$ müwu significa 'sangue' em wayana moderno. Os locutores nativos não reconhece no termo mune ou muno o significado de sangue, como pode-se encontrar em outras línguas caribes, como o aparai (Ver Camargo, 2002). 


\section{CONCLUSÃO}

Do ponto do vista gramatical, os dados analisados mostram diferentes valores de estado. Com -me expressa-se um estado contingente, com um valor incoativo ${ }^{27}$ que introduz uma dimensão evolutiva. Indicado aqui pelo morfema zero, $-\phi$, o estado permanente expressa, em cada instante referencial temporal, um processo subjacente em uma fase estável. Tal processo pode ser parafraseado pela relação entre dois termos como «X está Yndo», como sugerido em (4) kanawa-ø “a canoa está canoando”. Com o sufixo -tpë, faz-se referência ao estado anterior. Isto é, remete-se ao processo subjacente do estado de atividade acabado. Esta noção é muitas vezes expressa pelos falantes como "recente, recém, ex-". Os diferentes valores aspecto-temporais, marcados pelo operador -tpë, estão, em parte, ligados à natureza semântica do lexema ao qual se associa, expressando valores de 'terminar' e 'cessar', específicos de uma modalidade de ação (aktionsart). Eis aqui um aspecto fundamental de discussão de interesse para a tipologia da categoria aspecto-temporal, que vê «modalidades de ação» no âmbito mais lexical e menos gramatical.

Esta primeira análise do nome aspectualizado em wayana mostra que o 'aspecto' não se manifesta somente por morfemas gramaticais, o semantismo lexical também contribui para a significação da relação predicativa. O lexema codifica uma significação intrínseca, ou mais exatamente, uma rede de «esquemas semântico-cognitivos» ${ }^{28}$, visto que a natureza semântica do valor aspecto-temporal pode influir na semântica do lexema ao qual o morfema vem preso. Este estudo preocupou-se ainda em mostrar como esta língua codifica suas próprias representações cognitivas.

Por fim, vale ainda dizer que o nome aspectualizado não é um fenômeno restrito ao wayana ou às línguas caribes, como o tiriyó e o aparai. Ele também está presente em línguas tupi-guaranis, como o kamaiurá (Seki, 2000). Nesta língua do Alto Xingu, os morfemas - $\{$ r $\} a m$ e -het, interpretados respectivamente como 'atributivo' e 'passado nominal', parecem corresponder a -me, estado contingente, e a -tpë, estado de atividade acabado, do wayana. A aspectualização do nome pode ser um fenômeno corrente nessas duas famílias linguiísticas, porém quais são reais valores aspecto-temporais expressos ainda não foram revelados pela literatura existente.

\section{REFERENCIAS BIBLIOGRÁFICAS}

CAMARGO, E. (2000a) Une interaction entre localisation et aspect. Un exemple de -pëk\{ë $\}$ et -ja/e en wayana. Amerindia 25: 1-24. Paris: AEA.

.(2000b) L'ordre des constituants en wayana. Langue amérindienne du plateau guyanais. In A. Donabédian; Xu Dan (eds.). L'ordre des mots, Cahiers de Linguistique de l'INALCO (3), pp.147168. Paris: INALCO.

${ }^{27} \mathrm{O}$ tiriyó também conhece um valor incoativo associado ao nome, interpretado por Meira (1999:275) como verbalizador incoativo. Dentre as diferentes marcas apresentadas, a que pode se aproximar de -me seria - ma(mï). Infelizmente, o autor fornece poucos exemplos, e o apresentado koko 'noite' não corrobora com a realidade lingüística wayana, que aceita somente o estado em atividade para esse fenômeno natural.

${ }^{28}$ Ver Desclés 1991. 
(2002) Léxico bilíngüe aparai-português/português-aparai. München: Lincom Europa.

(2003a) Wayana, langues de France, pp. 281-283 (Dir) B. Cerquiglini. Paris: PUF.

(2003b) Relações sintáticas e relações semânticas da predicação nominal: a oração com cópula em wayana (caribe). Amerindia 28: 127-154. Paris: AEA

(2006a) Lexical categories and word formation processes in Wayana (Cariban language). In V. Vapnarsky; X. Lois (eds.). Lexical categories and Root Classes in Amerindian Languages, pp. 147-188. Zwitzerland: Peter Lang.

(2007a) Aspectos da sintaxe cindida em Wayana. In Andrés Romero-Figueroa; Ana Fernández Garay; Ángel Corbera Mori (eds.). Lenguas indígenas de América del Sur: Estudios descriptivotipológicos y sus contribuciones para la lingüística teórica, pp. 84-95. Caracas, Venezuela: Universidad Católica Andrés Bello. Caracas, Venezuela.

(2007b) Lieu et langue: paramètres d'identification et d'attribution du Soi et de l'Autre en wayana (caribe). In I. Léglise; B. Migge (eds.). Attitudes et représentations linguistiques en Guyane. Regards croisés, pp. 225-250. Paris: Éditons de 1'IRD, pp. 225-250.

DESCLÉS, J. P. (1989) State, event, process and topology. General Linguistics 29 (3): 159-200. .(1990) Langages applicatifs, langues naturelles et cognition. Paris: Hermès.

.(1991) Archétypes cognitifs et types de procès. Travaux de Linguistique et de Philologie XXIX: $171-195$.

(1993) Remarques sur la notion de processus inaccompli. Sémiotique, 5: 31-55.

DESCLÉS, J.P. ; Zl. GUENTCHÉVA. (1997) Aspects et modalités d'action. Représentations topologiques dans une perspective cognitive. Études cognitives 2: 146-173.

GILDEA, S. (1998) On reconstructing grammar. Comparative Cariban Morphosyntax.Oxford:Oxford University Press

JACKSON, W. (1972) A Wayana Grammar. In Joseph Grimes (ed.). Languages of the Guianas, pp. $47-$ 77. Oklahoma: SIL.

KOEHN, E. ; KOEHN, S. (1986). Apalaí. In Desmond C. Derbyshire; Geoffrey K. Pullum (eds.). Handbook of Amazonian Languages vol 1, pp. 33-127. Berlin: Mouton de Gruyter.

LAUNEY, M. (1994) Une grammaire omniprédicative. Essai sur la morphosyntaxe du nahuatl classique. Paris: Eds du CNRS.

MEIRA, S. (1999) A grammar of Tiriyo. Ph. D. Dissertation. Houston: Rice University.

SEKI, L. (2000) Gramática do kamaiurá. Língua tupi-guarani do Alto Xingu. Campinas: Editora da UNICAMP.

SHAUMYAN, S. (1977) Applicational grammar as a semantic theory of natural language. Chicago: Univewrsity of Chicago Press.

TAVARES, P. (2005) Grammar of Wayâna. Ph. D. Dissertations. Houston: Rice University. 


\section{Abreviaturas}

A(gente)

ALIEN(ável)

ANAF(órico)

ASS(ertivo)

AUM(entativo)

COMPL(eto)

EST(ado de) ATIV(idade)

EST(ado) ANT(erior)

EST(ado) RES(ultante)

EVOL(utivo)

INALIEN(ável)

INC(ompleto)

LIT(eral)

LOC(ativo)

NEG(ação)

$\mathrm{P}$ (aciente)

PERM(anente)

POS(sessivo)

PRED(icado)

PRIV(ativo)

SIT(uacional)

U(actante único)

Recebido: 5/11/2007

Versão Revista: 28/12/2008

Aceito: 6/1/2009 